American Journal of Applied Sciences 8 (2): 116-123, 2011

ISSN 1546-9239

(C) 2010 Science Publications

\title{
Plastic Membrane Electrodes of Coated Wire Type for Micro Determination of Quininium Cation in Pharmaceutical Tablets
}

\author{
${ }^{1}$ Laila Abdullah A1 Shatti, ${ }^{2}$ Hayat Mohammed Marafie \\ and ${ }^{2}$ Adel Fahmi Shoukry \\ ${ }^{1}$ Department of General Science, College of Nursing, \\ The Public Authority for Applied Education and Training, Kuwait State \\ ${ }^{2}$ Department of Chemistry, Faculty of Science, Kuwait University, Kuwait State
}

\begin{abstract}
Problem statement: Silver and copper all-solid state wire sensor electrodes of quininium cation with different ion exchangers have been prepared and used in pharmaceutical analysis. A comparative study with a reference method is applied in order to investigate the validity of the proposed method for potentiometric analysis of pharmaceutical compounds containing quinine. Approach: A Nernstian equation was proved for all electrodes of quinine in this research. Potentiometric investigations were carried out to identify the characteristic performance of the electrodes, such as the life span, $\mathrm{pH}$ effect and effect of the interfering ions. Chemometric and statistical studies of the chemical analysis of quinine in pharmaceutical compounds were applied using different type of electrodes compared to a reference method. Results: A Polyvinyl Chloride (PVC) membrane electrodes of silver (Ag) and Copper $(\mathrm{Cu})$ Coated Wire Electrodes (CWEs) were prepared for quininium cation $\left(\mathrm{Qn}^{+}\right)$. The ion exchangers were ion-pairs and ion associates of $\mathrm{Qn}+$ with different counter-anions, such as reineckate $\left(\mathrm{Rn}^{-}\right)$, phosphotungstate $\left(\mathrm{PT}^{3-}\right)$ and phosphomolybdate $\left(\mathrm{PM}^{3-}\right)$. The Qn-CWEs showed a Nernstian response for a maximum $24 \mathrm{~h}$ at $25^{\circ} \mathrm{C}$, except with that based on $\mathrm{Cu}$ $\mathrm{Qn}_{3} \mathrm{PM}$.Conclusion/Recommendations: The ion pair $\mathrm{QnRn}$ and the ion associates $\mathrm{Qn}_{3} \mathrm{PT}$ and $\mathrm{Qn}_{3} \mathrm{PM}$ are very efficient ion exchangers for the construction of Qn-CWEs. The performance characteristics (life span, $\mathrm{pH}$ effect and the selectivity) proved that such electrodes can be successfully used for the potentiometric micro-determination of $\mathrm{Qn}_{2} \mathrm{SO}_{4}$ in its pharmaceutical preparation. The analytical application showed that the recoveries and relative standard deviation of different Qn-CWEs reveals a high degree of accuracy and precision. In spite of their high accuracy, the F- test conclude the fact that the reference method is usually more precise than proposed method introduced in this study except for $\mathrm{Ag}-\mathrm{Qn}_{3} \mathrm{PM}$ electrode. In general, $\mathrm{Ag}-\mathrm{Qn}{ }_{3} \mathrm{PM} \mathrm{CWE}$ showed a discrete behavior regarding accuracy and silver metal preference. Further application of this type of electrodes on different pharmaceutical compounds is recommended to countervail the trends on the performance characteristics and confront the statistical parameters.
\end{abstract}

Key words: Most ion-Selective Electrodes (ISEs), Phosphotungstic Acid (PTA), polyvinyl chloride, pharmaceuticals samples, Separate Solution Method (SSM), Matched Potential (MPM), pharmaceutical compounds, reference method, plastic membrane

\section{INTRODUCTION}

Ion-selective electrode is an electrochemical sensor based on thin films or selective membranes as recognition elements in aqueous solutions. Coated Wire Electrodes (CWEs), introduced by Freiser in the mid1970 s, are prepared by $(\mathrm{Pt}, \mathrm{Ag}, \mathrm{Cu})$ or graphite-based with any conventional shape, such as wire or disk. The conductor is usually dipped in a solution of PVC and the active substance and the resulting film is allowed to air-dry. They are usually highly sensitive and very easy to use. An ion-selective membrane is the key component of all potentiometric ion sensors. The membrane establishes the preference with which the sensor responds to the analyte in the presence of various interfering ions (Lonsdale, 1982; Wang, 2006; Mirbaghei et al., 2007; Emamieh et al., 2008). Such a membrane is quite similar to liquid phase, because diffusion coefficients for dissolved low molecular weight ion-pairs or ion-associates are in the order of

Corresponding Author: Laila Abdullah Al Shatti, Department of General Science, College of Nursing, The Public Authority for Applied Education and Training, Kuwait State 
Am. J. Applied Sci., 8 (2): 116-123, 2011

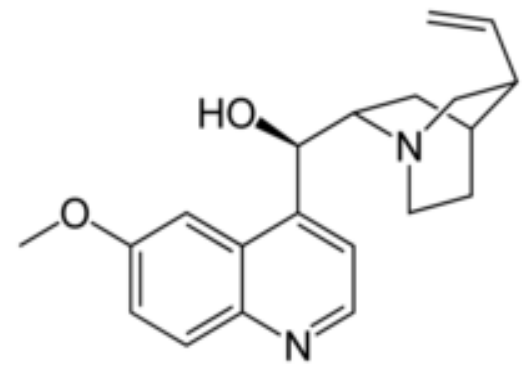

Fig. 1: Structural formula of quinine

$10^{-7}-10^{-8} \mathrm{~cm}^{2} \mathrm{sec}^{-1}$ (Mikehelson, 1994; Schaller et al., 1994; Jamhour, 2005; Saito et al., 2008). The ionselective electrode cell may be presented in conventional type or solid state coated wire types (Wang, 2006; Bakker et al., 1999; Bucj, 1978; Abdullah et al., 2010). Most ion-Selective Electrodes (ISEs) developed so far for determination of drugs are based on the use of ion-exchange systems. If the drug involves compounds containing organic cation, different salts are used for their conversion to an electrode-active ion-associate (Ngheim et al., 2006; Koryta, 1977; Stefan et al., 1997; Levenstam et al., 2005; Youging et al., 2006; Aly et al., 2005; Nakatani et al., 2005; Ma et al., 2005).

The CWEs based on ion-associate quininium and Reineckate, phosphotungstate and phosphomolybdate were found to give useful results for determination of quinine in pharmaceuticals samples (Sekula et al., 2006; Kobayashi et al., 2010; Zareh et al., 2001; Kamel and Sayour, 2009). In the reference method, the ISEs of the conventional type for quininium cation have been constructed and their performance characteristics studied (Shoukry et al., 2007). The results were very satisfactory; however the preparation of the electrodes needs multiple steps. This is because all solid state electrodes of the coated wire type are much more easily prepared than the conventional type and have the advantage of not containing internal reference electrode. The present study describes a further search for a satisfactory PVC electrode for determination of Quininium cation based on different metals-coated wire electrodes.

Figure 1, shows the figure of quinine (Dewick, 2009), which is an alkaloid derived from the bark of the cinchona tree. It is a natural white crystalline alkaloid having antipyretic, antimalarial, analgesic and antiinflammatory properties and a bitter taste. It is a stereoisomer of quinidine, which, unlike quinine, in an anti-arrhythmic. Several analytical methods have been developed for the quantitative determination of this drug. These methodologies include chromatography (Samanidou et al., 2005; 2004), spectrophotometry (Csernak et al., 2006; Hassan, 2008; Tang et al., 2005; Radhi et al., 2010).

\section{MATERIALS AND METHODS}

Materials: All chemicals used were of analytical grade. Polyvinyl chloride (PVC) of high molecular weight (Fluka). Dioctyl phthalate (Fluka), ammonium reineckate (Aldrich), phosphomolybdic acid (PMA) (Fluka) and Phosphotungstic Acid (PTA) (Fluka) were used. The Qn-containing tablets quininga $(300 \mathrm{mg} /$ tablet) are from Inga Pharma, Bombay. Sampling was carried out by grinding 10 tablets into fine powder, from which replicate samples were taken. All solutions and reagents were prepared in bi-distilled water. The $\mathrm{Qn}_{3} \mathrm{PT}$ and $\mathrm{Qn}_{3} \mathrm{PM}$ ion-associates and $\mathrm{QnRn}$ ion pair were prepared by a method similar to that previously described (Shoukry et al., 1988). The elemental analysis of the produced ion-exchangers carried out at ANALAB, Faculty of Science, Kuwait University confirmed the stochiometries: (1:1) (Qn: Rn), (3:1) $(\mathrm{Qn}: \mathrm{PT})$ and (3:1) (Qn:PM).

Construction of the electrodes: Spectroscopic pure silver or copper wires of $2.00 \mathrm{~mm}$ diameter and $12 \mathrm{~cm}$ length were tightly insulated by polyethylene tubes, leaving $1.0 \mathrm{~cm}$ at one end for coating and $0.5 \mathrm{~cm}$ at the other end for connection. The coating solution was prepared by dissolving $8.6,8.6$, or $11.0 \mathrm{mg}$ of the ionexchanger ( $\mathrm{QnRn}, \mathrm{Qn}_{3} \mathrm{PT}$ or $\mathrm{Qn}_{3} \mathrm{PM}$, respectively), in 4 $\mathrm{ml}$ tetrahydrofuran, $104 \mathrm{mg}$ of $\mathrm{PVC}$ and $102 \mathrm{mg}$ of DOP were dissolved. Prior to coating, the polished silver or copper surface was washed with a detergent and water, thoroughly rinsed with deionized water and dried with acetone. Then, the wire was rinsed with chloroform and allowed to dry. Afterward, the wire was coated by quickly dipping it into the coating solution several times and allowing the film left on the wire to dry in air for about $2 \mathrm{~min}$. The process was repeated three times until a plastic membrane of $1.00 \mathrm{~mm}$ thickness was formed. The prepared electrodes were preconditioned by soaking them for $1.5 \mathrm{~h}$ in $10^{-3} \mathrm{M}$ QnHCl solution (Shoukry et al., 2007).

Potentiometric studies and electrochemical systems: Potentiometric measurements were carried out with an Orion, Model 420A pH/mV meter. A Caron circulator thermostat was used to control the temperature of the test solution. 
Am. J. Applied Sci., 8 (2): 116-123, 2011

The following electrochemical system was employed:

$\mathrm{Ag} \mid \mathrm{AgCl}$ reference electrode $\mid \mathrm{QnCl}$ Test solution $\mid \mathrm{Ag}$ or $\mathrm{Cu}$ coated membrane $|\mathrm{AgCl}| \mathrm{Ag}$

Construction of the calibration graphs: Suitable increments of standard QnCl solution were added to 50 $\mathrm{mL}$ of $10^{-6} \mathrm{M} \mathrm{QnCl}$ solution so as to cover the concentration range $10^{-6} \mathrm{M}-1.7 \times 10^{-2} \mathrm{M}$. In this solution, the sensor and the reference electrode were immersed and the Electro-Motive Force (EMF) was recorded after $10 \mathrm{~s}$, at $25^{\circ} \mathrm{C}$ for each addition.

Life span of the electrodes: The performance characteristics of the electrodes were investigated as a function of soaking time. For this purpose, the electrode was soaked in a solution with $10^{-3} \mathrm{M}$ in $\mathrm{QnCl}$ and the calibration graphs ( $p Q n$ vs $\mathrm{E}_{\mathrm{mv}}$ ) were constructed after $0.5,1,2$ and $24 \mathrm{~h}$.

Effect of $\mathbf{p H}$ : The $\mathrm{pH}$ of the test solution was altered by the addition of small volumes of $\mathrm{HNO}_{3}$ and/or $\mathrm{NaOH}$ (0.1-1.0 M each). Graphs of ( $\mathrm{pH}$ vs $\mathrm{E}_{\mathrm{mv}}$ ) were plotted showing the effect of $\mathrm{pH}$ on different silver or copper coated wire electrodes of the different ionexchangers.

Selectivity: The selectivity coefficients of the Qnselective electrode, $\left(\mathrm{K}_{\mathrm{Qn}, \mathrm{j}}^{\mathrm{pot}}\right)$ towards different cationic species $\left(\mathrm{j}^{\mathrm{z}}\right)$ were determined by the Separate Solution (SSM) (Cosofret, 1991) and Matched Potential (MPM) (Umezawa et al., 1995).

Analytical application: The studied CWEs were used (by applying the standard addition method) to determine $\mathrm{Qn}_{2} \mathrm{SO}_{4}$ in the pharmaceutical preparation, quininga tablets. In this method, small aliquots of a standard solution- $0.1 \mathrm{M}$ of QnCl-were added to the tablet sample solution; the ionic strength of the medium was kept constant at about $0.01 \mathrm{M}$ with $\mathrm{NaNO}_{3}$. The difference in potential before and after the standard addition was used to calculate the sample solution content of Qn.

\section{RESULTS}

Life span of the electrodes: The soaking of the electrode is important to form a hydrated gel layer at its surface and consequent good performance characteristics (Nernstian slope, response time $5 \mathrm{~s}$ and low usable concentration range at $25^{\circ} \mathrm{C}$ ). The CWEs were soaked in $10^{-3} \mathrm{M} \mathrm{QnCl}$ solution and the calibration graphs of $\mathrm{Ag}$ - and $\mathrm{Cu}$-wire electrodes for QnRn were plotted after 0.5, 1, 2 and $24 \mathrm{~h}$ (Fig. 2). It is clear from Table 1 that Ag-and $\mathrm{Cu}$-CWEs exhibit good Nernstian performance characteristics. The soaking taking place up to $24 \mathrm{~h}$ for both types of electrodes has no effect on the calibration graph slope, except for with $\mathrm{Cu}-\mathrm{Qn}_{3} \mathrm{PM}$ which has a short life span.

Effect of pH: The pH effect on the potential values of the electrode system of the quinine test solution was tested by the alteration of $\mathrm{pH}$ values using $\mathrm{HNO}_{3}$ and /or $\mathrm{NaOH}$ within the range of $\mathrm{pH} 2.00-11.00$. Aliquots of $50.0 \mathrm{~mL}$ were transferred to a $100.0 \mathrm{~mL}$ titration cell and the tested ion-selective electrode in conjugation with an $\mathrm{Ag} / \mathrm{AgCl}$ reference electrode and a combined $\mathrm{pH}$ glass electrode being immersed in the same solution. The $\mathrm{mV}$ - readings were plotted against the $\mathrm{pH}$-values for the quinine in Fig. 3. The electrode reading is constant whatever the $\mathrm{pH}$ value for the average range (3.2-7.6). In this range, the electrode can be used satisfactorily for Qn determinations in biological fluids.

Selectivity: The selectivity coefficients $\mathrm{K}_{\mathrm{Qn}, \mathrm{J}}^{\mathrm{pot}}{ }_{\mathrm{q}}^{\mathrm{z}}$ of the CWEs for quininga pharmaceutical of quininerespective drug towards the major serum cations (Schenk et al., 2009; Asadi et al., 2009), $\mathrm{Na}^{+}, \mathrm{K}^{+}, \mathrm{Mg}^{2+}$ and $\mathrm{Ca}^{2+}$ were determined by the Separate Solution Method (SSM) and matched potential (MPM) as described previously (Cosofret, 1991; Umezawa et al., 1995), where the following equation was applied for (SSM):

$\log \mathrm{K}_{\mathrm{Qn}, \mathrm{J}}^{\mathrm{pot}}=\mathrm{E}_{2}-\mathrm{E}_{1} / \mathrm{s}+\log \left[\mathrm{Qn}^{+}\right]-\log \left[\mathrm{J}^{\mathrm{Z}^{+}}\right]^{1 / \mathrm{z}}$

where, $\mathrm{Qn}^{+}$is quininium cation; $\mathrm{J}^{\mathrm{z}}$ is the interfering ion; $E_{1}$ and $E_{2}$ is the electrode potential in $10^{-3} \mathrm{M}$ solution of $\mathrm{Qn}^{+}$and $\mathrm{J}^{\mathrm{z}}$, respectively; and (s) is the slope of the calibration graph. The reciprocal value of the selectivity coefficient represents the minimum concentration ratio of the interfering ion to the primary ion at which interference start. Table 2 lists the mean selectivity coefficients of Qn-CWEs determined by both (SSM) and (MPM). The selectivity coefficients of the CWEs' values are very small (within maximum $2.65 \times 10^{-2}$ to the minimum $3.45 \times 10^{-4}$ for $\mathrm{K}^{+}$and $\mathrm{Mg}^{2+}$, respectively). Consequently, it will reflect no interference of the major serum cations. Multiplying 
Am. J. Applied Sci., 8 (2): 116-123, 2011

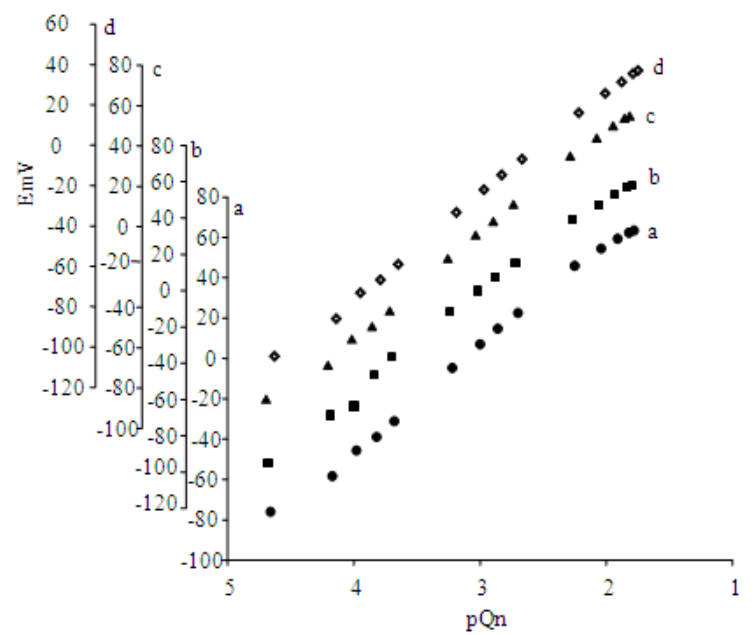

(a)

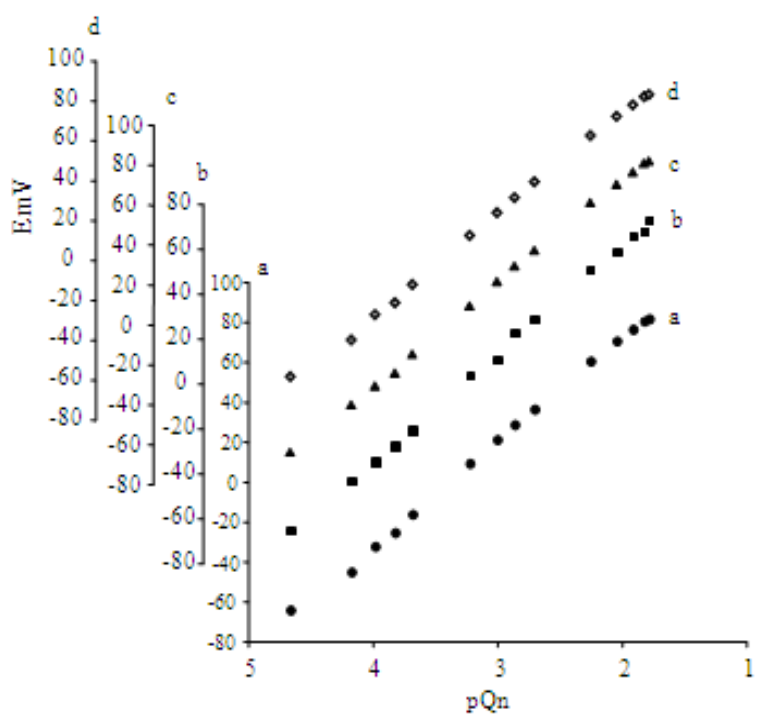

(b)

Fig. 2: Calibration graph obtained at $25^{\circ} \mathrm{C}$ after soaking Ag-QnRn (top) in $10^{-3} \mathrm{M} \mathrm{Qn}^{+}$-solution for a: 0.5, b: 1, c: 2 and d: 24 hours and (below) Cu-QnRn

the selectivity coefficient by the concentration of the interfering ion produces the minimum concentration of the drug that can be detected in the blood serum without interference. Applying this mathematical treatment using the serum concentrations of the cations, it is evident that with down to $4.90 \times 10^{-4}, 1.96 \times 10^{-5}$, $3.45 \times 10^{-7}$ and $8.04 \times 10^{-5} \mathrm{M}$ Qn concentrations, in case of Ag-QnRn electrode and down to $4.00 \times 10^{-4}$, $1.81 \times 10^{-5}, \quad 2.88 \times 10^{-6}$ and $5.64 \times 10^{-6} \mathrm{M} \quad \mathrm{Qn}$ concentrations, in case of $\mathrm{Cu}-\mathrm{QnRn}$ electrode, no interference of $\mathrm{Na}^{+}, \mathrm{K}^{+}, \mathrm{Mg}^{2+}$ and $\mathrm{Ca}^{2+}$, respectively, is expected. Homologous calculations of different QnCWEs are represented in Table 2.

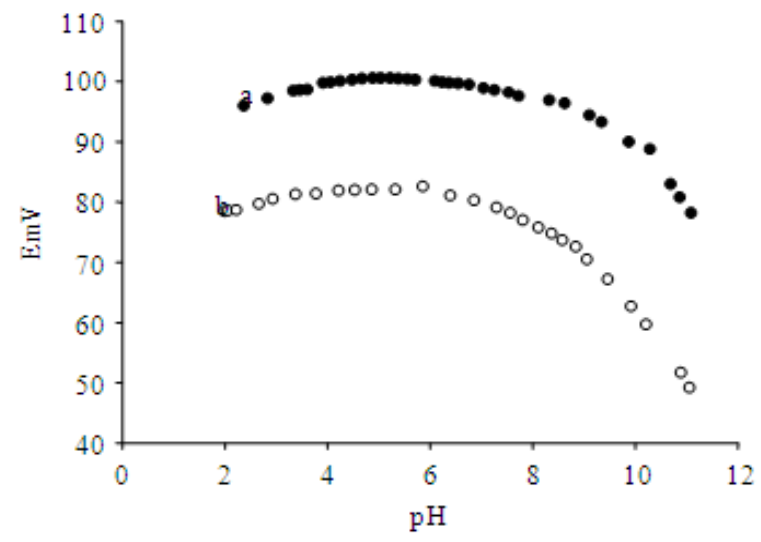

Fig. 3: Effect of $\mathrm{pH}$ of the test solution on the $\mathrm{Qn}^{+}$ responsive electrode in (a) $1 \times 10^{-3}$ and (b) $1 \times 10^{-4} \mathrm{M}$ solution at $25^{\circ} \mathrm{C}$

Analytical application: From the results shown in Table 3, it is evident that the measurements in general exhibit low values of standard deviation (s), ranging from 0.64 when using $\mathrm{Ag}-\mathrm{Qn}_{3} \mathrm{PM}$ to 1.45 when using $\mathrm{Cu}-\mathrm{QnRn}$ for assaying tablets. The recovery values using Ag-CWEs were 100.9, 97.77 and 97.60 for $\mathrm{Qn}_{3} \mathrm{PM}, \mathrm{Qn}_{3} \mathrm{Pt}$ and QnRn, respectively. The recovery values using $\mathrm{Cu}-\mathrm{CWEs}$ were 93.30, 92.80 and 91.89 for $\mathrm{QnRn}, \mathrm{Qn}_{3} \mathrm{Pt}$ and $\mathrm{Qn}_{3} \mathrm{PM}$, respectively. The recovery values obtained for the analysis of $\mathrm{Qn}$ in the tablets reflect the high accuracy of the method.

\section{DISCUSSION}

Life span of the electrodes: The soaking for up to $24 \mathrm{~h}$ for both types of electrodes has no effect on the calibration graph slope (Fig. 2). However, after $24 \mathrm{~h}$ soaking, the slope decreases gradually and the linear usable concentration range is greatly affected by soaking shown in Table 1. This may be attributed to gradual leaching of the electro active ion-exchanger from the membrane surface.

Effect of pH: Graphs of ( $\mathrm{pH}$ vs $\mathrm{E}_{\mathrm{mv}}$ ) show the same trends for all Qn-CWEs (Fig. 3). They have the shape of a plateau form in an average $\mathrm{pH}$ range from 3.2-7.6 and the $\mathrm{pH}$ decreased in both acidic and basic sides of the curve. This phenomenon allows the QnCWEs a good working range in blood serum since the $\mathrm{pH}$ of blood ranges from 7.35-7.45. For all QnCWEs, it is clear that at $\mathrm{pH}$ values extended to lower or higher values than the plateau ranges of the curves, the potential values decrease with decreasing and increasing the $\mathrm{pH}$, respectively. 
Am. J. Applied Sci., 8 (2): 116-123, 2011

Table 1: Effect of soaking on the performance of Qn-electrodes

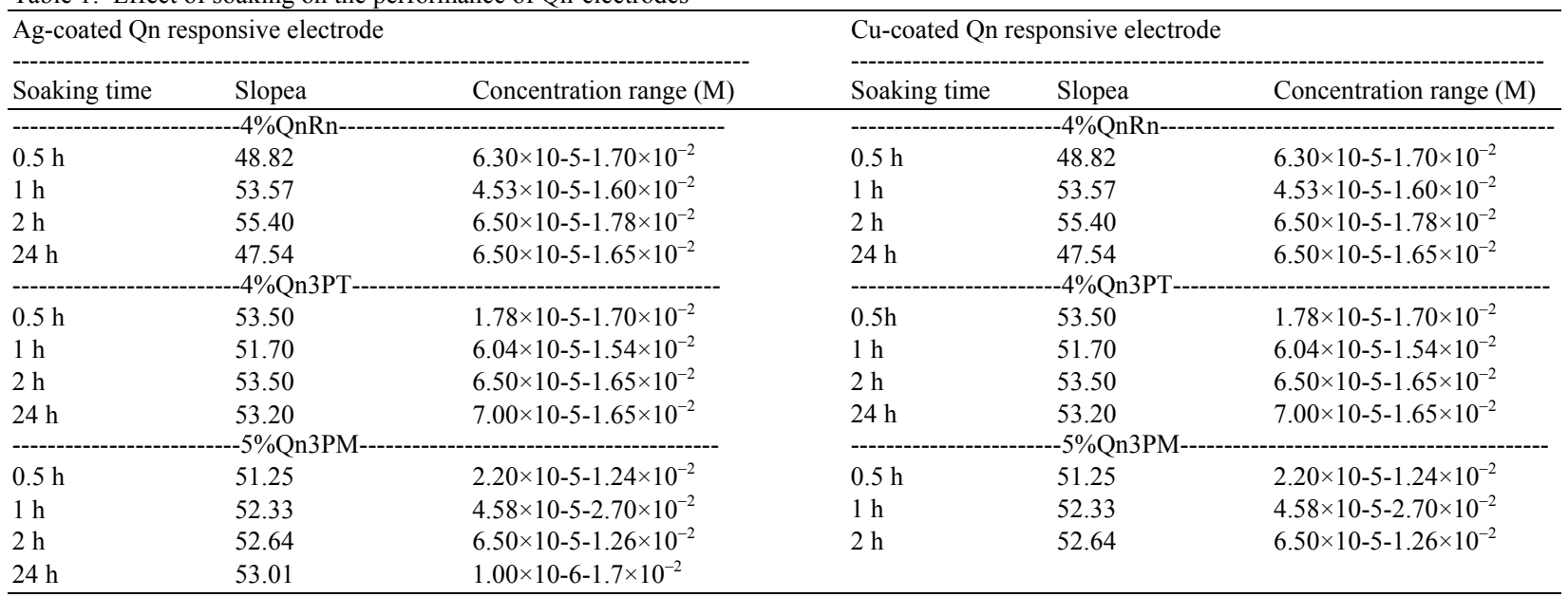

${ }^{\mathrm{a}} \mathrm{mV} / \mathrm{Qn}$ concentration decade

Table 2: Selectivity coefficients $\mathrm{K}_{\mathrm{Qn}, \mathrm{J}}^{\mathrm{pot}}$ of Qn-responsive metal coated $(\mathrm{Ag}, \mathrm{Cu})$ electrodes

\begin{tabular}{|c|c|c|c|c|c|}
\hline \multirow{2}{*}{\multicolumn{2}{|c|}{ Interfering ion }} & \multicolumn{4}{|c|}{ Selectivity coefficient KpotQn,Jz+ } \\
\hline & & \multirow{2}{*}{$\begin{array}{l}\text { Mean value } \\
\mathrm{Ag}\end{array}$} & \multirow{2}{*}{$\begin{array}{l}\text { Mean value } \\
\mathrm{Cu}\end{array}$} & \multirow[b]{2}{*}{$\mathrm{Ag}$} & \multirow{2}{*}{$\begin{array}{l}\text { dMmin. } \\
\mathrm{Cu}\end{array}$} \\
\hline Cation & Blood serum Level M & & & & \\
\hline \multirow[t]{3}{*}{$\mathrm{Na}+$} & 0.14 & ${ }^{\mathrm{a}} 3.53 \times 10^{-3}$ & ${ }^{\mathrm{a}} 2.84 \times 10^{-3}$ & ${ }^{\mathrm{a}} 4.90 \times 10^{-4}$ & ${ }^{\mathrm{a}} 4.00 \times 10^{-4}$ \\
\hline & & ${ }^{b} 2.30 \times 10^{-2}$ & ${ }^{b} 1.85 \times 10^{-2}$ & $\mathrm{~b}_{3} 3.22 \times 10^{-3}$ & ${ }^{b} 2.60 \times 10^{-3}$ \\
\hline & & ${ }^{c} 2.25 \times 10^{-2}$ & ${ }^{\mathrm{c}} 1.94 \times 10^{-2}$ & ${ }^{c} 3.15 \times 10^{-3}$ & ${ }^{\mathrm{c}} 2.72 \times 10^{-3}$ \\
\hline \multirow[t]{3}{*}{$\mathrm{K}+$} & 0.005 & $3.92 \times 10^{-3}$ & $3.62 \times 10^{-3}$ & ${ }^{\mathrm{a}} 1.96 \times 10-5$ & ${ }^{\mathrm{a}} 1.81 \times 10^{-5}$ \\
\hline & & $\mathrm{b}_{3.72 \times 10^{-2}}$ & ${ }^{b} 2.05 \times 10^{-2}$ & $\mathrm{~b}_{1} 1.86 \times 10^{-3}$ & ${ }^{\mathrm{b}} 1.03 \times 10^{-4}$ \\
\hline & & ${ }^{c} 2.65 \times 10^{-2}$ & ${ }^{\mathrm{c}} 1.86 \times 10^{-2}$ & ${ }^{\mathrm{c}} 1.33 \times 10^{-4}$ & ${ }^{\mathrm{c}} 9.30 \times 10^{-5}$ \\
\hline \multirow[t]{3}{*}{$\mathrm{Mg} 2+$} & 0.001 & $3.45 \times 10^{-4}$ & $2.88 \times 10^{-3}$ & $3.45 \times 10^{-7}$ & ${ }^{\mathrm{a}} 2.88 \times 10^{-6}$ \\
\hline & & $\mathrm{b}_{2} .23 \times 10^{-3}$ & ${ }^{\mathrm{b}} 1.68 \times 10^{-2}$ & $\mathrm{~b}_{2} .23 \times 10^{-6}$ & ${ }^{b} 1.68 \times 10^{-5}$ \\
\hline & & ${ }^{\mathrm{c}} 1.82 \times 10^{-3}$ & ${ }^{\mathrm{c}} 1.38 \times 10^{-2}$ & ${ }^{\mathrm{c}} 1.82 \times 10^{-6}$ & ${ }^{\mathrm{c}} 1.38 \times 10^{-5}$ \\
\hline \multirow[t]{3}{*}{$\mathrm{Ca} 2+$} & 0.003 & a $2.68 \times 10^{-4}$ & ${ }^{\mathrm{a}} 1.88 \times 10^{-3}$ & $8.04 \times 10^{-7}$ & a) $5.64 \times 10^{-6}$ \\
\hline & & $b_{2} .75 \times 10^{-3}$ & $\mathrm{~b} 1.47 \times 10^{-2}$ & $\mathrm{~b}_{8} .25 \times 10^{-6}$ & ${ }^{\mathrm{b}} 4.41 \times 10^{-5}$ \\
\hline & & ${ }^{c} 1.83 \times 10^{-3}$ & ${ }^{\mathrm{c}} 1.35 \times 10^{-2}$ & ${ }^{\mathrm{c}} 5.50 \times 10^{-6}$ & ${ }^{c} 4.05 \times 10^{-5}$ \\
\hline
\end{tabular}

${ }^{\mathrm{a}}: \mathrm{QnRn} ;{ }^{\mathrm{b}}: \mathrm{Qn}_{3} \mathrm{PT} ;{ }^{\mathrm{c}}: \mathrm{Qn}_{3} \mathrm{PM} ;{ }^{\mathrm{d}}:$ Minimum concentration of drug detected in blood serum without interference

Table 3: Applying three different Qn-responsive electrodes to the determination of Qn in the pharmaceutical tablets, Quininga, using the standard addition method

\begin{tabular}{|c|c|c|c|c|c|c|c|}
\hline \multirow[b]{2}{*}{ Ion exchanger } & \multirow[b]{2}{*}{$\begin{array}{l}\text { Labeled } \\
\text { amount (mg) }\end{array}$} & \multicolumn{3}{|c|}{ Amount found (mg) ${ }^{\mathrm{a}}$} & \multicolumn{3}{|c|}{$(\%)$ Recovery $^{b}$} \\
\hline & & $\mathrm{Ag}$ & $\mathrm{Cu}$ & $\begin{array}{l}\text { Reference method } \\
\text { (Shoukry et al., 2007) }\end{array}$ & $\mathrm{Ag}$ & $\mathrm{Cu}$ & $\begin{array}{l}\text { Reference method } \\
\text { (Shoukry et al., 2007) }\end{array}$ \\
\hline$\overline{Q n R n}$ & 78.29 & $\begin{array}{l}76.34 \pm 1.02 \\
F=2.7 \\
t=17.55\end{array}$ & $\begin{array}{l}73.04 \pm 1.45 \\
F=1.37 \\
t=6.22\end{array}$ & $79.87 \pm 1.70$ & $97.60 \pm 1.30$ & $93.30 \pm 1.86$ & 102.00 \\
\hline Qn3PT & 78.29 & $\begin{array}{l}76.52 \pm 0.65 \\
F=16.5 \\
t=2.45\end{array}$ & $\begin{array}{l}72.66 \pm 0.67 \\
F=17.54 \\
t=3.3\end{array}$ & $76.11 \pm 0.16$ & $97.77 \pm 0.87$ & $92.80 \pm 0.84$ & 97.22 \\
\hline Qn3PM & 78.29 & $\begin{array}{l}79.04 \pm 0.639 \\
F=7.08 \\
t=0.76\end{array}$ & $\begin{array}{l}71.94 \pm 0.73 \\
F=5.423 \\
t=7.6\end{array}$ & $79.79 \pm 1.70$ & $100.9 \pm 0.82$ & $91.89 \pm 0.93$ & 101.90 \\
\hline
\end{tabular}

${ }^{a}$ Mean \pm standard deviation of five determinations, the $\mathrm{t}$ - and F- test values refer to comparison of the proposed method with the reference method of four determinations. Theoretical values of $95 \%$ confidence limit, $\mathrm{F}_{(4,3)}=9.12, \mathrm{~F}_{(3,4)}=6.59, \mathrm{t}_{7}=2.36$, ${ }^{\mathrm{b}} \mathrm{After}$ adding different amounts of the pure labeled to the pharmaceutical formulations, each value is an average of five determinations

The decrease in potential at the acidic side of the curves is most probably due to nitrate ion interface. On the other hand, the decrease in potential at the basic side of the curve is attributed to the decrease of quinine cationic species $\left(\mathrm{Qn}^{+}\right)$as a result of releasing the free base from the pharmaceutical compound. 
Selectivity: The selectivity of an ion pair complexbased membrane depends on the ion exchange process at the membrane test interface and the mobility of the respective ions in the membrane. None of the investigated ions was found to interfere due to small values of the selectivity coefficients in Table 2 . The minimum molarities of the drug detected in blood serum without interference by Qn-CWEs were mostly of a micro-scale, except for with $\mathrm{Na}^{+}$cation. This shows that both Ag- and $\mathrm{Cu}-\mathrm{CWEs}$ are so selective for quininium that they can be used conveniently in the determination of quininium in the pharmaceutical preparations and biological fluids.

Analytical application: The statistical t- and F-tests were used to analyze the data in Table 3, starting from calculating the mean and the standard deviation of each determination for the applied Ag- and $\mathrm{Cu}-\mathrm{CWEs}$. The results show that the present $\mathrm{CWEs}$ of $\mathrm{Ag}$ and $\mathrm{Cu}$ are highly accurate (as shown by the recovery values) and highly precise (as revealed by the corresponding standard deviations).

To compare the efficiency of the two metal electrodes with respect to the reference method, the tand F-test were applied. In making a significant test we are testing the truth of a hypothesis which is known as a null hypothesis, often denoted by $\mathrm{H}_{0}$. The term null is used to imply that there is no difference between the mean, $\mathrm{x}^{-}$and the true values, $\mu$, of the proposed and reference values $\left(\mu_{1}=\mu_{2}\right)$. In other words, we need to test whether $\mathrm{x}_{1}^{-}$and $\mathrm{x}_{2}^{-}$differ significantly from zero by the application of a t-test. The calculated $|t|$ values of $\mathrm{Ag}-\mathrm{QnRn}, \mathrm{Cu}-\mathrm{QnRn}, \mathrm{Ag}-\mathrm{Qn}_{3} \mathrm{PT}, \mathrm{Cu}-\mathrm{Qn}_{3} \mathrm{PT}$ and $\mathrm{Cu}-$ $\mathrm{Qn}_{3} \mathrm{PM}$ are each higher than the critical value $\mathrm{t}_{7}=2.36$. Accordingly, the difference between the two results of the reference and the proposed methods is significant at $5 \%$ level and the null hypothesis is rejected. In fact, since the critical value of $t_{7}$ for 0.01 is about 3.5 , the difference is significant at $1 \%$ level except for $\mathrm{Ag}$ $\mathrm{Qn}_{3} \mathrm{PT}$. In other words, if the null hypothesis is true, then the probability of such a large difference arising by chance is less than $1 \%$. The $\mathrm{Ag}-\mathrm{Qn}_{3} \mathrm{PM}$ calculated value $\left(\mathrm{t}_{7}=0.76\right)$ is less than the critical value $\left(\mathrm{t}_{7}=\right.$ 2.36), so the null hypothesis is retained and there is no evidence that using the conventional or Ag-CWE affects the recovery.

Another significance test that describes the precisions of the proposed method with a reference method is the F-test. The F-test is used for comparing whether the difference between two sample variances is significant (i.e., to test $H_{0}: \sigma_{1}^{2}=\sigma_{2}^{2}$ ). If the null hypothesis is true, then the variance ratio should be close to 1 . The F-values calculated were 2.7, 1.37 and
5.423 for Ag-QnRn, $\mathrm{Cu}-\mathrm{QnRn}$ and $\mathrm{Cu}-\mathrm{Qn}_{3} \mathrm{PM}$, respectively, which are less than Critical $\mathrm{F}_{(3,4)}$ (6.59). Since the calculated values are less than the critical values of $F$, the variance of the proposed method is significantly greater than that of the reference method at $5 \%$ probability level (i.e., the reference method is more precise). Comparatively, $\mathrm{Ag}-\mathrm{Qn}_{3} \mathrm{PM}$ calculated $\mathrm{F}_{(3,4)}$ (7.08) is higher than critical $F_{(3,4)}(6.59)$, which means that the $\mathrm{Ag}-\mathrm{Qn}{ }_{3} \mathrm{PM}$ is more precise than the reference method. Conversely, the calculated $\mathrm{F}_{(4,3)}$ values were found to be 16.5 and 17.54 for $\mathrm{Ag}-\mathrm{Qn}_{3} \mathrm{PT}$ and $\mathrm{Cu}-$ $\mathrm{Qn}_{3} \mathrm{PT}$, respectively. The calculated values were higher than critical $F_{(4,3)}(9.12)$, which mean that (in case of $\left.\mathrm{Qn}_{3} \mathrm{PT}\right)$ the reference method is more precise than with $\mathrm{Cu}-\mathrm{Qn}{ }_{3} \mathrm{PT}$ or $\mathrm{Ag}-\mathrm{Qn}_{3} \mathrm{PT}$.

\section{CONCLUSION}

The ion pair QnRn and the ion associates $\mathrm{Qn}_{3} \mathrm{PT}$ and $\mathrm{Qn}_{3} \mathrm{PM}$ are efficient ion exchangers for the construction of Qn-CWEs. Such electrodes can be successfully used for the micro determination of $\mathrm{Qn}_{2} \mathrm{SO}_{4}$ in its pharmaceutical preparation. The chemometric study concludes that the reference method is usually more than the proposed method except for Ag$\mathrm{Qn}_{3} \mathrm{PM}$. In general, $\mathrm{Ag}-\mathrm{Qn}_{3} \mathrm{PM} \mathrm{CWE}$ showed a discrete behavior regarding accuracy and silver metal preference.

\section{ACKNOWLEDGEMENT}

The cooperation of Kuwait University-College of Science through the facilities of Analytical Laboratory (ANALAB) with The Public Authority for Applied Education and Training in the integration of the scientific research.

\section{REFERENCES}

Abdullah, W., M. Othman, M. Ali and M.S. Islam, 2010. Knowledge representation of ion-sensitive field-effect transistor voltage response for potassium ion concentration detection in mixed potassium/ammonium ion solutions. Am. J. Applied Sci., 7: 81-88. DOI: 10.3844/ajassp.2010.81.88

Aly, A.S., H.H. Sokker, A. Hashem and A. Habiesh, 2005. Preparation of cellulosic membrane containing pyrrolidone moiety via radiation induced grafting and its application in wastewater treatment. Am. J. Applied Sci. 2: 508-513. DOI: 10.3844/ajassp.2005.508.513 
Asadi, A., B. Haut, M. Hassim, T. Mohamed and M. Hanafi et al., 2009. Electroosmotic phenomena in organic soils. Am. J. Environ. Sci., 5: 310-314. DOI: 10.3844/ajessp.2009.310.314

Bakker, E., P. Buhlmann and E. Pretsch, 1999. Polymer membrane ion-selective electrodes-what are the limits. Electroanal., 13: 915-933. DOI: 10.1002/(SICI)15214109(199909) $11: 13<915::$ AIDELAN915>3.0.CO;2-J

Bucj, R.P., 1978. Ion selective electrodes. Anal. Chem., 50: 17-29. DOI: 10.1021/ac50028a003

Cosofret, V.V., 1991. Drug membrane sensors and their pharmaceutical applications. TrAC Trends Analytical Chem., 10: 298-301. DOI: 10.1016/0165-9936(91)85008-F

Csernak, O., A. Buvari-Barcza and L. Barcza, 2006. Cyclodextrin assisted nanophase determination of alkaloid salts. Talanta, 69: 425-429. DOI: 10.1016/j.talanta.2005.10.010

Dewick, P.M., 2009. Medicinal Natural Products: A Biosynthetic Approach. 3rd Ed., John Wiley and Sons Publisher, Canada, ISBN: 978-0-470-741689, pp: 550.

Emamieh, G.D., A. Ameri, S. Najarian and A.T. Golpavgani, 2008. Experimental and theoretical analysis of a novel flexible membrane tactile sensor. Am. J. Applied Sci., 5: 122-128. DOI: 10.3844/ajassp.2008.122.128

Hassan, W., 2008. Determination of ibuprofen and paracetamol in binary mixture using chemometricassisted spectrophotometric methods. Am. J. Applied Sci., 5: 1005-1012. DOI: 10.3844/ajassp.2008.1005.1012

Jamhour, R.M.A.Q., 2005. New inorganic ion-exchange material for the selective removal of fluoride from potable water using ion-selective electrode. Am. J. Environ. Sci., 1: 1-4. DOI: 10.3844/ajessp.2005.1.4

Kamel, A.H. and H.E.M. Sayour, 2009. Flow-through assay of quinine using solid contact potentiometric sensors based on molecularly imprinted polymers. Electroanal., 21: 2701-2708. DOI: 10.1002/elan.200904699

Kobayashi, Y., M. Habara, H. Ikezaki, R. Chen and Y. Naito et al., 2010. Advanced taste sensors based on artificial lipids with global selectivity to basic taste qualities and high correlation to sensory scores. Sensors, 10: 3411-3443. DOI: 10.3390/s100403411

Koryta, J., 1977. Theory and applications of ionselective electrodes part II. Anal. Chim. Acta., 1: 1-85. DOI: 10.1016/S0003-2670(01)95921-5

Levenstam, A., M.M. Zurawska and A. Hulanicki, 2005. Application of ion-selective electrodes in clinical analysis. Electroanal., 3: 727-734. DOI: 10.1002/elan.1140030802
Lonsdale, H.K., 1982. The growth of membrane technology. J. Memb. Tech., 10: 81-181. DOI: 10.1016/S0376-7388(00)81408-8

Ma, X., R. Yang and G. Li, 2005. Hydrogen peroxide biosensor based on the direct electrochemistry of myoglobin immobilized in poly-3-hydroxybutyrate film. Am. J. Biochem. Biotechnol., 1: 43-46. DOI: 10.3844/ajbbsp.2005.43.46

Mikehelson, K.N., 1994. Ion-Selective Electrodes in PVC Matrix. Sen. Acutators B: Chem., 18: 31-37. DOI: 10.1016/0925-4005(94)87051-9

Mirbaghei, A., J. Dargahi, S. Najarian, F. and T. Ghomoshe, 2007. Design, fabrication and testing of membrane piezoelectric tactile sensor with four sensing elements. Am. J. Applied Sci., 4: 649-652. ISSN: 1546-9239

Nakatani, H.S., L.V. Santos and C.P. Pelegrine, S.T.M. Gomes and M. Matsushita et al., 2005. Biosensor based on Xanthine oxidase for monitoring hypoxanthine in fish meat. Am. J. Biochem. Biotechnol., $\quad 1$ : $\quad 85-89$. DOI: 10.3844/ajbbsp.2005.85.89

Ngheim, L.D., P. Morrane, I.D. Potter, J.M. Perera and R.W. Cattrall et al., 2006. Extraction and transport of metal ions and small organic compounds using polymer inclusion membranes (PIMs). J Memb. Sci., 281: 7-41. DOI: 10.1016/j.memsci.2006.03.035

Radhi, M.M., W.T. Tan, M.Z. Rahman and A.B. Kassim, 2010. Voltammetric detection of $\mathrm{Mn}(\mathrm{II})$ in blood sample at C60 and MWCNT modified glassy carbon electrodes. Am. J. Applied Sci., 7: 395-401. DOI: 10.3844/ajassp.2010.395.401

Saito, T., H. Fujimaki and M. Inova, 2008. Calibration and simultaneous monitoring of soil water content and salinity with capacitance and four-electrode probes. Am. J. Environ. Sci., 4: 683-692. DOI: 10.3844/ajessp.2008.683.692

Samanidou, V., E. Evaggelpoulou and I. Padaoyannis, 2004. Simple and rapid HPLC method for the determination of quinine in soft drinks using fluorescence detection. J. Liq. Chromatog. Rel. Technol., 27: 2397-2406. DOI: 10.1081/JLC200028156

Samanidou, V., E. Evaggelpoulou and I. Padaoyannis, 2005. Simultaneous determination of quinine and chloroquine anti-malarial agents in pharmaceuticals and biological fluids by HPLC and fluorescence detection. J. Pharm. Biomed. Anal., 38: 21-28. DOI: 10.1016/j.jpba.2004.12.005

Schaller, U., E. Bakker, U.E. Spichiger and E. Pretsch, 1994. Ionic additives for ion-selective electrodes based on electrically charged carriers. Anal. Chem., 66: 391-398. DOI: 10.1021/ac00075a013 
Schenk, G.H., R.B. Hahn and A.V. Hartkope, 2009. Introduction to Analytical Chemistry. 2nd Ed, Allyn and Bacon Publish Publisher, London, UK, ISBN: 0205072364, pp: 523.

Sekula, J., J. Everaert, H. Bohets, B. Vissers and M. Pietraszkiewicz et al., 2006. Coated wire potentiometric detection for capillary electrophoresis studied using organic amines, drugs and biogenic amines. Anal. Chem., 78: 3772-3779. DOI: $10.1021 / \mathrm{ac060066y}$

Shoukry, A.F., H.M. Maraffie and L.A. Al Shatti, 2007. Energy dispersive and $\mathrm{X}$-ray photoelectron spectroscopy and electron microscopy of new quininium-plastic membrane electrodes. Annal. Di. Chim., 97: 1117-1127. DOI: 10.1002/adic.200790095

Shoukry, A.F., S.S. Badawy and R. Farghali, 1988. Hexadecylpyridinium-phosphotungstate ion association in construction of a Hexadecylpyridinium cation selective electrode. Anal. Chem., 60: 2399-2402. DOI: 10.1021/ac00172a016

Stefan, R., G.E. Baiulescu and H.Y. Aboul-enien, 1997. Ion-selective membrane electrodes in pharmaceutical analysis. Crit. Rev. Anal. Chem., 27: 307-321. DOI: 10.1080/10408349708050589
Tang, G., Y. Huang and W. Shi, 2005. Reverse micellebased chemiluminescence system for quinine sulphate. Lumines, 20: 181-186. DOI: 10.1002/bio.816

Umezawa, A.Y., K. Umezawa and S.H. Ato, 1995. Selectivity coefficients for ion-selective electrodes: Recommended methods for reporting $\mathrm{K}_{\mathrm{A}}, \mathrm{B}^{\text {pot }}$ values (Technical Report), Pure Appl. Chem., 67: 507-518. DOI: 10,1351/pac199567030507

Wang, J., 2006. Analytical Electrochemistry. 3rd Ed. John Wiley and Sons Publisher, Canada, ISBN 13: 9780471678793, pp: 272.

Youging, M., C. Jianrong and W. Xiahua, 2006. Construction of a glucose biosensor by immobilizing glucose oxidase within a poly(ophenylenediamine) covered screen-printed electrode. Online J. Biol. Sci., 6: 18-22. DOI: 10.3844/ojbsci.2006.18.22

Zareh, M.M., E. Malinowska and K. Kasiura, 2001. Plasticized poly(vinyl chloride) membrane electrode for the determination of quinine in soft drinks. Anal. Chim. Acta., 447: 55-61. DOI: 10.1016/s0003-2670(01)01005-4 